\title{
Field Measurements of Wind Turbine Wakes with Lidars
}

\author{
Giacomo Valerio Iungo, Yu-Ting Wu, And Fernando Porté-Agel \\ Wind Engineering and Renewable Energy Laboratory, École Polytechnique Fédérale de Lausanne, Lausanne, Switzerland
}

(Manuscript received 28 February 2012, in final form 14 September 2012)

\begin{abstract}
Field measurements of the wake flow produced from a 2-MW Enercon E-70 wind turbine were performed using three scanning Doppler wind lidars. A GPS-based technique was used to determine the position of the wind turbine and the wind lidar locations, as well as the direction of the laser beams. The lidars used in this study are characterized by a high spatial resolution of $18 \mathrm{~m}$, which allows the detailed characterization of the wind turbine wake. Two-dimensional measurements of wind speed were carried out by scanning a single lidar over the vertical symmetry plane of the wake. The mean axial velocity field was then retrieved by averaging 2D scans performed consecutively. To investigate wake turbulence, single lidar measurements were performed by staring the laser beam at fixed directions and using the maximum sampling frequency. From these tests, peaks in the velocity variance are detected within the wake in correspondence of the turbine top tip height; this enhanced turbulence could represent a source of dangerous fatigue loads for downstream turbines. The spectral density of the measured velocity fluctuations shows a clear inertial-range scaling behavior. Then, simultaneous measurements with two lidars were performed in order to characterize both the axial and the vertical velocity components. For this setup, the two velocity components were retrieved only for measurement points for which the two laser beams crossed nearly at a right angle. Statistics were computed over the sample set for both velocity components, and they showed strong flow fluctuations in the near-wake region at turbine top tip height, with a turbulence intensity of about $30 \%$.
\end{abstract}

\section{Introduction}

Wind energy infrastructure and production have been growing rapidly over the last few decades as wind energy has become one of the most profitable sources of renewable energy. Optimizing the design and operation of wind farms requires understanding the complex interaction between atmospheric boundary layer flow and wind turbines. Of particular interest is the effect of wind turbine wakes, which are responsible for a reduction in power output and an increase in fatigue loads in wind farms; see, for example, Crespo et al. (1999) and Vermeer et al. (2003).

Computational fluid dynamics (CFD) techniques with different degrees of complexity and accuracy have been applied to simulate wind turbine wake flows. Early CFD tools have adopted the Reynolds-averaged Navier-Stokes (RANS) approach, in which the mean flow is computed

\footnotetext{
Corresponding author address: G. V. Iungo, Wind Engineering and Renewable Energy Laboratory (WIRE), École Polytechnique Fédérale de Lausanne, Station 2, 1015 Lausanne, Switzerland. E-mail: valerio.iungo@epfl.ch
}

and the effects of the turbulence are parameterized using closure models (Xu and Sankar 2000; Alinot and Masson 2002; Sørensen et al. 2002; Gomez-Elvira et al. 2005; Tongchipakdee et al. 2005; Sezer-Uzol and Long 2006; El Kasmi and Masson 2008). More recently, largeeddy simulation (LES) frameworks have also been developed for wind energy applications. LES computes explicitly large energy-containing nonuniversal scales of the flow, while the small scales are modeled (Jimenez et al. 2007, 2008; Calaf et al. 2010; Lu and Porté-Agel 2010, 2011; Porté-Agel et al. 2011; Wu and Porté-Agel 2011). In LES, the wind turbine-induced loads, that is, thrust and torque, can be parameterized using three different types of wind turbine models (see Porté-Agel et al. 2011; Wu and Porté-Agel 2011, 2013): an actuator disk model that distributes uniformly the loads over the rotor disk area; an actuator disk model with azimuthal rotation; and an actuator line model that distributes the forces along a lifting line that rotates, mimicking the blade motion.

All the above-mentioned numerical models need a significant amount of experimental data for their assessment and optimization. Experimental research in 
wind energy consists mainly in wind tunnel tests and field measurements. Wind tunnel investigations present the advantage of reproducing a broad range of wellcharacterized wind conditions. However, the used downscaled models represent a strong limitation, especially for the near wake, where geometrical details of the models might produce significant discrepancies with respect to real wind turbine flows. Moreover, the lower Reynolds number achieved in wind tunnel tests creates differences in the boundary layer flows over the blades with respect to real wind turbines, which can lead to differences for wind turbine loads. For example, Alfredsson et al. (1982) reported a lower maximum power coefficient for downscaled wind turbine models.

A review on wind tunnel investigations performed in the wind energy field is provided by Vermeer et al. (2003). Early investigations were performed on wind turbine static simulators, for example, in Builtjes (1978), Vermeulen and Builtjes (1982). Then, tests with rotating models were carried out considering also the interaction between different wind turbine wakes (Ross 1979; Ross and Ainslie (1981)). Several wind tunnel studies were performed to investigate the influence on the wake of different parameters, such as the downstream distance between wind turbine rows (Ross and Ainslie 1981; Green and Alexander 1985; Green 1986; Talmon 1985), turbine thrust coefficient (Milborrow and Ross 1983; Talmon 1985; Green 1986) and ambient turbulence (Alfredsson et al. 1980; Milborrow and Ross 1983; Zhang et al. 2012). Among the most recent wind tunnel studies, it is worth mentioning the analysis of the effect of the turbulent incoming flow on the wake structure presented in Medici and Alfredsson (2006). In that study, the effect of the yaw angle of the wind turbine on its wake was also investigated. The effect of the surface roughness on the wake turbulence is surveyed in Chamorro and PortéAgel (2009), whereas the influence of a stable and unstable thermal stratification on power production was considered in Chamorro and Porté-Agel (2010) and Zhang et al. (2013). Turbulent flow inside and above wind farms and its effect on turbine performance were investigated by Cal et al. (2010), Chamorro and PortéAgel (2011) and Markfort et al. (2012).

Besides the above-mentioned research activities, field measurements of wake flows produced by real wind turbines are also necessary in order to avoid issues connected to lower Reynolds number reproduced in wind tunnel tests or to uncertainties associated with turbulence and turbine simulations. A great challenge for field measurements is represented by the very large measurement volumes involved, and the often nonstationary and nonhomogeneous nature of atmospheric boundary layer flows. Field measurements are considered an essential tool for a proper estimation of the incoming wind field, which is extremely important for an accurate prediction of wind turbine power production. In Wagner et al. (2009) wind shear along the wind turbine height is considered for power prediction instead of only using the wind velocity at hub height. The characterization of the incoming turbulence is also important to evaluate fatigue loads on the blades, especially within a wind farm. Moreover, a proper characterization of the incoming mean wind and turbulence levels is fundamental to predict wake recovery, which is an essential feature for wind farm design.

Current industry standards for field measurements in wind energy consist mainly in tests performed with masts instrumented with sonic anemometers, cup anemometers, wind vanes, and temperature probes (Amar et al. 2008; Belu and Koracin 2009). However, conventional mast measurements are often insufficient to characterize flows produced by large wind turbines because of the limited number of measurement locations. Furthermore, the relative position between the mast and the wind turbine wake can vary depending on wind direction, wind turbine yaw angle, and wake meandering. Therefore, in order to avoid these measurement issues, the use of remote sensing techniques is growing rapidly for wind energy applications, in particular the use of sodars and short-range wind Doppler lidars.

A Doppler wind light detection and ranging (lidar) is a remote sensing instrument that measures wind velocity through the evaluation of the Doppler shift along a laser beam emitted into the atmosphere and backscattered because of the presence of particles. Therefore, a Doppler wind lidar is only sensitive to the velocity component parallel to the laser beam, the so-called radial velocity or line of sight (LOS) velocity. Lidar measurements can be performed by simply staring the laser beam along a fixed direction - that is, with fixed azimuth and elevation angles-which enables measuring the radial velocity along the beam direction at several locations evenly spaced along the beam. Two-dimensional measurements can be performed by scanning the lidar over vertical planes, the so-called range-height indicator (RHI), that is, by scanning the lidar with a fixed azimuthal angle and by varying its elevation angle. Measurements over conical surfaces can be also performed by varying the azimuth angle and with a fixed elevation angle, the so-called plan position indicator (PPI) or velocity-azimuth display (VAD).

More sophisticated techniques enable the measurement of 2D or 3D velocity fields by scanning consecutively a single lidar along different directions; see Newsom et al. (2005), Chan and Shao (2007), Xia et al. (2008), Lin et al. (2008), and Kongara et al. (2010). All 
these data retrieval methods are based on the assumption that within the measuring volume, the velocity is considered constant over planes orthogonal to the radial direction connecting the measurement point and the lidar location. Therefore, these methods cannot be used for wind turbine wake measurements where the velocity is changing rapidly within the wake. Furthermore, in Sathe et al. (2011) it is shown that turbulence cannot be measured with an adequate accuracy through conical scanning and VAD data retrieval. To investigate multicomponent velocity fields for wind turbine wakes, measurements carried out with multiple lidars must be considered, like the ones presented in Calhoun et al. (2006), Newsom et al. (2008), Mann et al. (2009), Drechsel et al. (2009), and Hill et al. (2010).

Doppler wind lidars have been extensively used for meteorological investigations in the last decades (see Gal-Chen et al. 1992; Frelich et al. 1998; Newsom et al. 2005; Retallack et al. 2010). Regarding wind energy, reliability of vertical wind profiles obtained with a Leosphere windcube wind lidar was investigated by Aitken et al. (2012). The authors found that lidar performance is influenced by aerosol backscatter, atmospheric refractive turbulence, humidity, and precipitation. These results suggest that lidar measurements are very useful for wind turbine siting and wind farm design. In Kasler et al. (2010), lidar measurements were used to detect the velocity deficit within wind turbine wakes; however, the long-range wind lidar used in that study did not allow characterizing in detail the wake flow. A review on remote sensing techniques for wind energy applications is provided by Emeis et al. (2007).

In this paper, lidar measurements of the wake produced from an Enercon E-70 2 MW wind turbine are presented. First, measurements with one lidar staring along a fixed direction were performed by varying the number of laser rays emitted for each velocity profile. Then, the mean wake velocity field was obtained by averaging $2 \mathrm{D}$ measurements performed over vertical sections of the wake. Measurements were also performed by staring a single lidar over selected fixed directions with the maximum sampling frequency and for a sampling period of about $11 \mathrm{~min}$. The main goal of these tests was the detection of wake regions with a higher turbulence intensity. Finally, simultaneous measurements with two lidars were carried out over the vertical symmetry plane of the wake in order to retrieve vertical and axial velocity components, while a third lidar characterized the incoming flow.

The paper is organized as follows: the tested wind turbine, the site, and the used lidars are described in section 2. The $1 \mathrm{D}$ and $2 \mathrm{D}$ wake measurements performed with a single lidar are then reported in section 3, whereas simultaneous measurements with three lidars are presented in section 4. Finally, conclusions are provided in section 5 .

\section{Wind turbine site and experimental setup}

The field campaign was performed during the period between June and August 2011, and measurements were performed during daytime between 1200 and 2000 local time (LT), when generally a north-northwest wind blows. The tests mainly consist of lidar measurements of the wake flow produced from the interaction between the atmospheric boundary layer and two wind turbines located in the towns of Collonges and Martigny, respectively, of the Canton de Valais in Switzerland. The wind turbine locations are reported on the map in Fig. 1a, whereas a street view of the site is shown in Fig. $1 b$. These wind turbines are located within a narrow valley surrounded by mountains with heights around $2500 \mathrm{~m}$. Thus, the topography plays a strong role on the wind characteristics. The wind turbine in Martigny is mainly surrounded by fruit trees with a maximum height of about $4 \mathrm{~m}$, whereas the one in Collonges is surrounded by cornfields and grass fields.

The two wind turbines considered in this study were manufactured by Enercon and are operated by RhôneEole SA. The one in Martigny, called Mont d'Ottant, is an E-82, while the one in Collonges, called Cime de l'Est, is an E-70. In this study only measurements performed for the latter are presented. Technical data of the wind turbine E-70 Cime de l'Est are reported in Table 1. It has a rotor diameter of $71 \mathrm{~m}$, a hub height of $98 \mathrm{~m}$, and a maximum capacity of $2.3 \mathrm{MW}$. Annual power production of this wind turbine is reported in Table 2.

The supervisory control and data acquisition (SCADA) data of the tested wind turbine were acquired for the whole testing period. These data include the rotational velocity of the wind turbine blades, the wind velocity measured at hub height from an anemometer mounted on the nacelle, the wind turbine yaw angle, and power production; each parameter was recorded as averages over 10-min periods. In Fig. 2a a histogram of the mean hub height wind velocity is reported. It shows that during summertime, the considered site is characterized by a moderate wind with typical velocities between 5 and $10 \mathrm{~m} \mathrm{~s}^{-1}$. Regarding wind direction, the one with the highest incidence is at $340^{\circ}$ from north (see Fig. 2b), which typically occurs in the afternoon hours during the testing period. This wind is a thermal wind blowing from the warmer area of Lake Geneva toward the Alps, and is mainly canalized along the valley. The other common wind blows roughly in the opposite direction, that is, south-southeast $160^{\circ}$ from north, typically in the early 


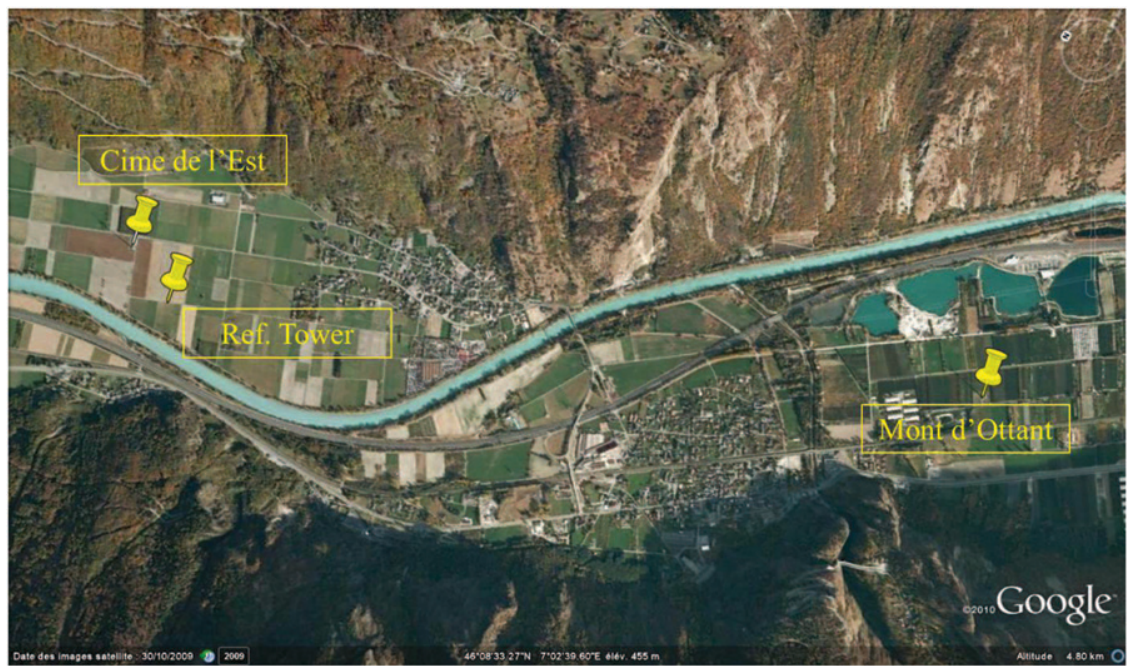

(a)

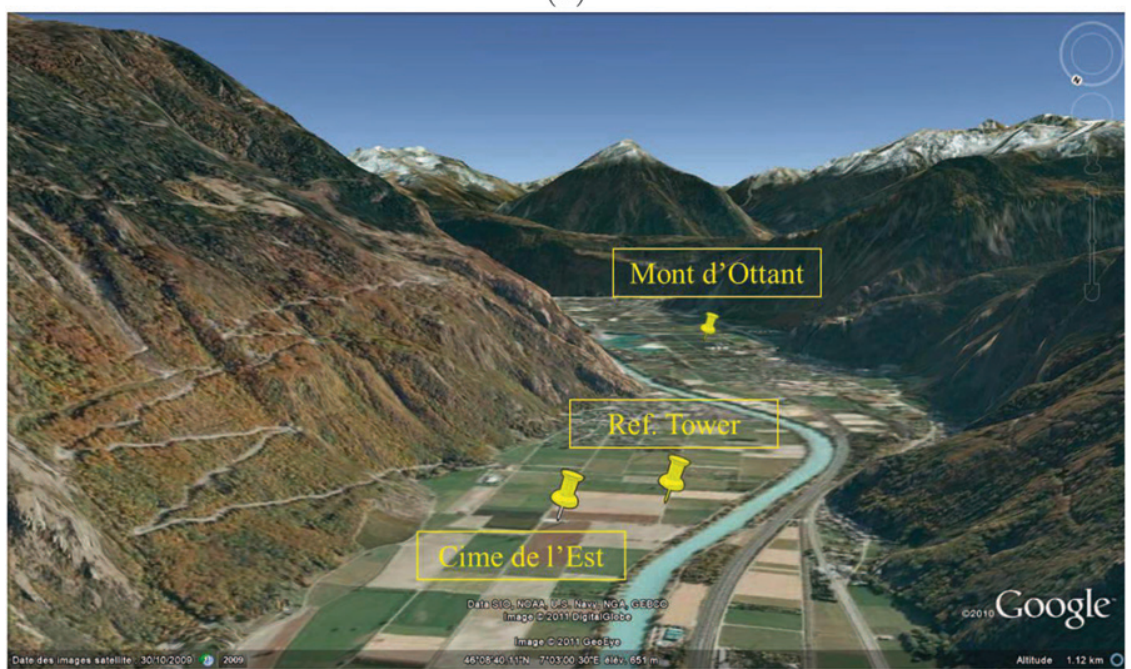

(b)

FIG. 1. Wind turbine site: (a) map and (b) street view.

morning and slightly stronger than the north-northwest wind. The wind conditions recorded during the testing period are summarized in the wind rose reported in Fig. 3.

Wind turbine performance is also investigated through the SCADA data, as the wind turbine rotational velocity reported in Fig. 2c. From this histogram, a roughly uniform occurrence of rotational velocities between 8 and $21 \mathrm{rpm}$ is observed, except for a higher percentage in correspondence of the value $19 \mathrm{rpm}$. Finally, the histogram of the power production over 10-min intervals is shown in Fig. 2d.

Wind velocity measurements were performed with three Galion Doppler wind lidars, produced by Halo Photonics. This pulsed Doppler wind lidar emits wave trains with a wavelength of $1.5 \mu \mathrm{m}$ and a frequency of $15 \mathrm{kHz}$. The direction of the lidar laser beam is controlled by setting different values of the azimuth and elevation angles. One-dimensional measurements at several points evenly spaced along the laser beam can be performed by staring the lidar along a fixed direction. On the other hand, two-dimensional vertical scans of the wind field can be performed by varying the elevation angle of the laser and maintaining fixed the azimuthal angle, that is, the so-called RHI scans. It is also possible to perform measurements over conical surfaces by varying the azimuthal angle and keeping a fixed elevation angle, which are denoted as PPI or VAD scans. All the main characteristics of the Galion lidar are reported in Table 3, among them it is worth highlighting the relatively high spatial resolution of $18 \mathrm{~m}$. The first available measurement point is at a distance of $40 \mathrm{~m}$ from the lidar location, and the maximum range is about $3 \mathrm{~km}$. The maximum sampling frequency is $0.77 \mathrm{~Hz}$. 
TABLE 1. Technical data of the wind turbine Enercon E-70 Cime de l'Est.

\begin{tabular}{ll}
\hline \hline Rotor diameter $(\mathrm{m})$ & 71 \\
Hub height $(\mathrm{m})$ & 98 \\
Rated power $(\mathrm{kW})$ & 2300 \\
GPS coordinates & $569^{\prime} 000 / 112^{\prime} 125$ \\
Height over sea level $(\mathrm{m})$ & 450 \\
Turbine concept & Gearless, variable speed, \\
& single-blade adjustment \\
Rotor type & Upwind with pitch control \\
Rotational direction & Clockwise \\
No. of blades & 3 \\
Swept area $\left(\mathrm{m}^{2}\right)$ & 3959 \\
Blade material & GRP \\
Rotational speed $(\mathrm{rpm})$ & $6-21.5$ \\
Cutout wind speed $\left(\mathrm{m} \mathrm{s}^{-1}\right)$ & $28-34$ \\
\hline
\end{tabular}

The exact location of the wind turbines, a reference electrical tower, and the lidars were determined using a GPS. Moreover, azimuthal displacements of the lidar laser beam were also evaluated through the GPS in order to reach the measurement targets, as it will be described in the following sections. The GPS used is the GRS-1 by Topcon, which works with GPS and Global Navigation Satellite System (GLONASS) receivers. This GPS can achieve a precision of $300 \mathrm{~mm}$ with a differential GPS (DGPS) network, which was typically used for this study, but an increased precision of $15 \mathrm{~mm}$ can be achieved with a real-time kinematic (RTK) network.

The reference frame used for this field campaign has its origin placed on the ground level at the wind turbine location. The $x$ axis corresponds to the mean wind direction, which was measured from a wind vane located in proximity of the wind turbine at a height of $4 \mathrm{~m}$, positive in the downstream direction. The $z$ axis is along the vertical direction, positive from the bottom to the top, while the $y$ axis is along the spanwise direction.

\section{Wind turbine wake measurements performed with a single lidar}

First, measurements were performed with a single lidar in order to assess the accuracy of the mean radial velocity measurements and to characterize the frequency resolution for the analysis of velocity fluctuations. The Galion lidar enables varying the number of laser rays emitted for each velocity measurement; in fact, the radial velocity is retrieved from the average Doppler effect measured on a certain number of emitted laser rays. For a chosen number of laser rays emitted for a single velocity profile, this technique allows for obtaining a higher sampling frequency and the reduction of the measurement error compared to performing measurements with a single emitted ray and then computing statistics of measurements performed consecutively. To
TABLE 2. Annual wind power production of the wind turbine Cime de l'Est.

\begin{tabular}{cc}
\hline \hline Year & $\begin{array}{c}\text { Annual power } \\
\text { production }(\mathrm{kWh})\end{array}$ \\
\hline 2006 & 4388954 \\
2007 & 4289149 \\
2008 & 4805210 \\
2009 & 4942000 \\
2010 & 4818937 \\
\hline
\end{tabular}

evaluate the effects of varying the number of emitted laser rays on the radial velocity measurements, tests were performed with one lidar placed at a distance of nine rotor diameters $d$ downstream of the wind turbine along the mean wind direction. Regarding the lidar pointing procedure, the location of the wind turbine was detected by gradually varying the azimuthal angle while pointing the laser beam at hub height for a horizontal distance equal to the distance between the lidar and the turbine. The wind turbine location was clearly detectable from a strong peak of the intensity of backscattered light corresponding to the side edges of the turbine at positions $(0, \pm d / 2, H)$, where $H$ is hub height. The correct orientation of the lidar is further verified by changing the azimuthal angle to detect the position of a reference electrical tower (see Fig. 1).

Measurements were performed by staring the laser beam along a fixed direction with an elevation angle of $11.8^{\circ}$, and passing through the point located at a downstream distance $x=0.5 d$ and the same height as the turbine top tip. Tests were carried out by setting a different number of laser rays emitted for each velocity profile and by measuring for a sampling period of $5 \mathrm{~min}$. In Fig. 4a statistics of the radial velocity are reported for the case of one laser ray emitted for each measurement. For this case the sampling time, that is, the time required for a single measurement, is $1.3 \mathrm{~s}$. In Fig. 4 the mean value and standard deviation of the radial velocity are reported for each measurement point along the laser beam. The first two points at a radial distance smaller than $40 \mathrm{~m}$ should not be considered because they are located at a distance lower than the minimum range of the lidar. A clear reduction in mean wind velocity is observed near the wind turbine due to the presence of the wake. As expected, the level of velocity fluctuations is slightly increased in that region. For the remaining points located upstream of the wind turbine, a larger standard deviation is generally observed, which can be attributed to the lower accuracy of the signal. This feature could be because the energy of the laser beam decreases as the square root of the radial distance; thus, the signal-to-noise ratio decreases with increasing radial distance. Moreover, it appears that the concentration 


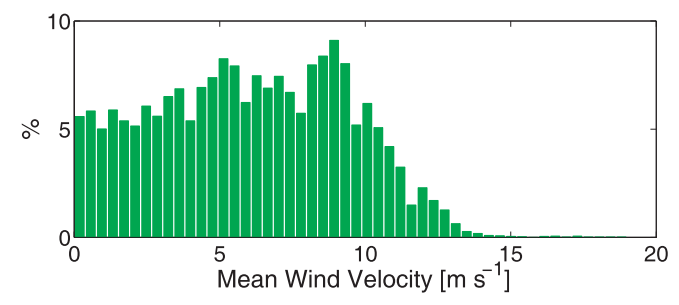

(a)

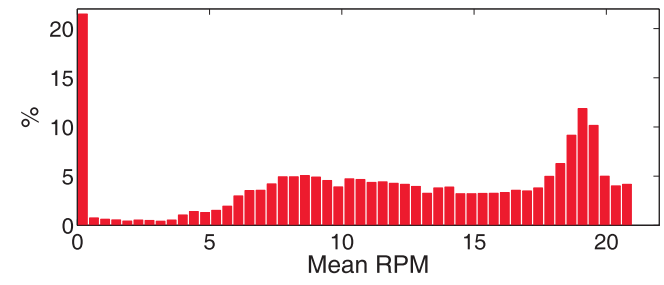

(c)

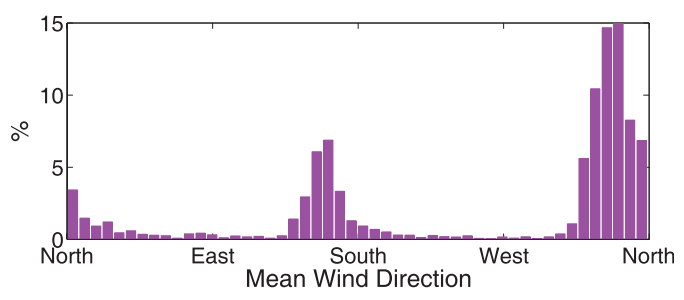

(b)

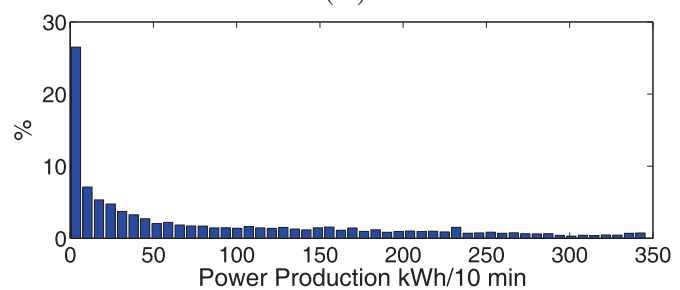

(d)

FIG. 2. Histograms of the SCADA data recorded during the testing period June-August 2011 with a sampling time of 10 min: (a) mean wind velocity, (b) mean wind direction, (c) mean rotational velocity of the wind turbine (rpm), and (d) mean power production.

of aerosols is lower outside of the wake and at higher elevations.

By increasing the number of rays emitted for each measurement to 4 , it is observed in Fig. $4 \mathrm{~b}$ that the variability of the measurements is generally reduced in the turbine wake. This is most probably due to the larger averaging time of $5 \mathrm{~s}$, thus filtering out the velocity fluctuations produced by turbulent eddies with characteristic time scales smaller than the sampling time. Finally, if the case of 64 rays is considered (see Fig. 4c),

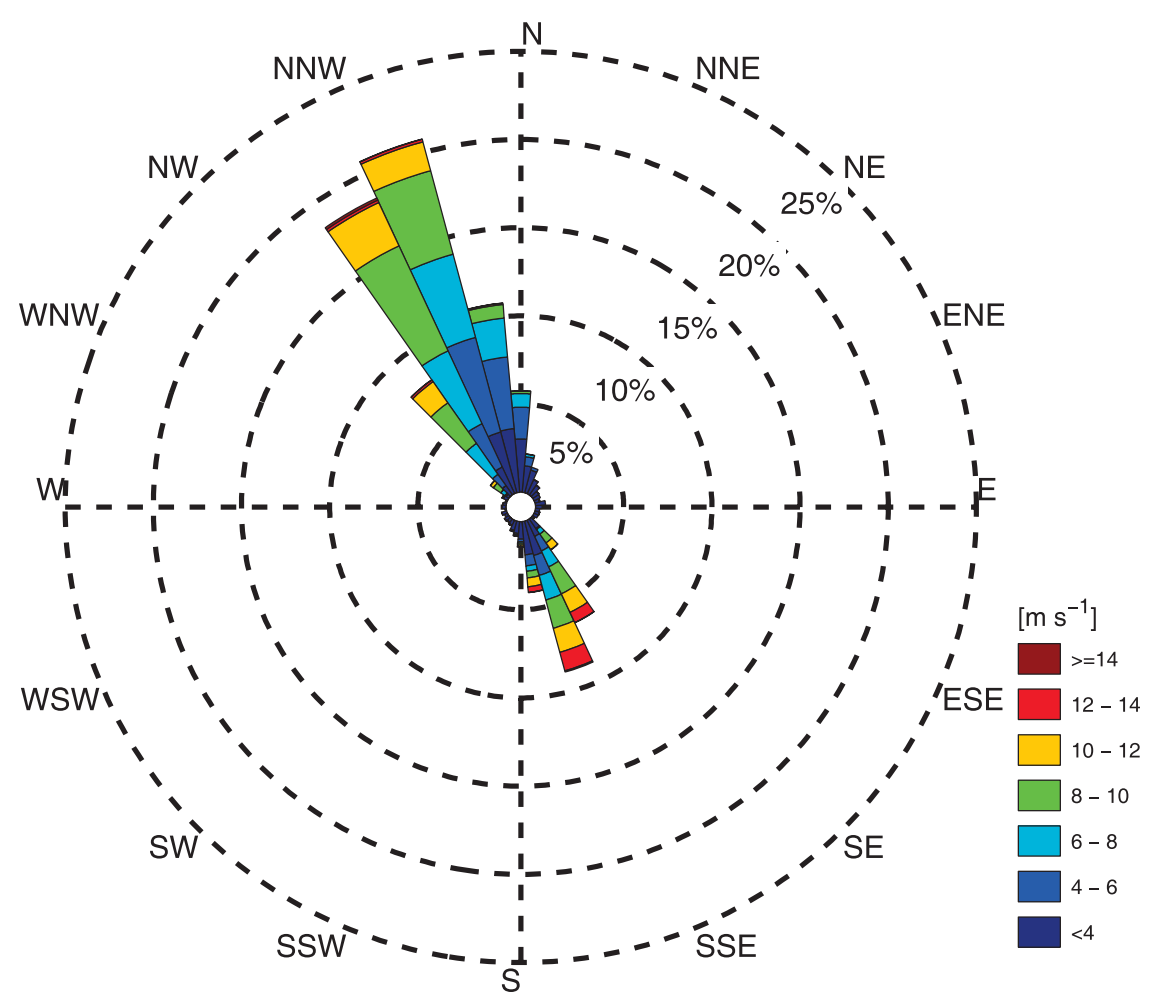

FIG. 3. Wind rose evaluated from the SCADA data for the period June-August 2011. 
TABLE 3. System and data acquisition parameters of the Galion Doppler wind lidar produced by Halo Photonics.

\begin{tabular}{lc}
\hline \hline Wavelength $(\mu \mathrm{m})$ & 1.5 \\
Repetition rate $(\mathrm{kHz})$ & 15 \\
Telescope aperture $(\mathrm{mm})$ & 50 \\
Measurement range & from $40 \mathrm{~m}$ up to $3 \mathrm{~km}$ \\
Width of lidar range gates $(\mathrm{m})$ & 18 \\
No. of range gates used & 166 \\
Max sampling rate between & 0.77 \\
$\quad$ two scans $(\mathrm{Hz})$ & \\
\hline
\end{tabular}

then it is evident that the variability of the mean radial velocity is drastically reduced also for measurement points located upstream of the wind turbine, which is due to the long averaging time of $74 \mathrm{~s}$.

Summarizing, the number of laser rays emitted for each velocity profile can be increased in order to enhance the accuracy of the mean radial velocity, especially for experimental cases with low aerosol concentration or for measurements performed at large radial distances, for example, between 2 and $3 \mathrm{~km}$. For the present experimental campaign, wake measurements were typically performed by using one laser ray because the considered measurement volume is at a radial distance smaller than $1.5 \mathrm{~km}$. Furthermore, it has been observed that at a fixed radial distance from the lidar, the signal accuracy is generally higher for measurements of wind turbine wakes than for typical atmospheric boundary layer cases. This higher signal-to-noise ratio might be due to wake turbulence and to a higher aerosol concentration produced from flow entrainment into the wind turbine wake, which is promoted by the lower pressure present within the wake. It is important to point out that performing measurements with one ray allows for maximizing the sampling frequency and, thus, the investigation of wake turbulence.

Measurements with a single lidar were also performed with the RHI technique, that is, by scanning the lidar with a fixed azimuthal angle and varying the elevation angle. The lidar was placed at a distance of $6.5 d$ downstream of the wind turbine location along the mean wind direction. By setting the azimuthal angle on the direction of the center of the turbine, 2D lidar measurements were performed over the mean vertical symmetry plane of the wind turbine wake. Considering the reference frame introduced in section 2 , the vertical symmetry plane of the wake is determined by the $x$ and $z$ axes. The tests were performed by using one ray for each velocity profile and by covering the wake region with 41 different laser elevation angles evenly spaced by $1^{\circ}$. Each 2D vertical scan required $41 \mathrm{~s}$, and consecutive measurements were typically performed for periods of 15 min. In Fig. 5 several 2D maps of the wake flow are reported. These figures show the axial velocity

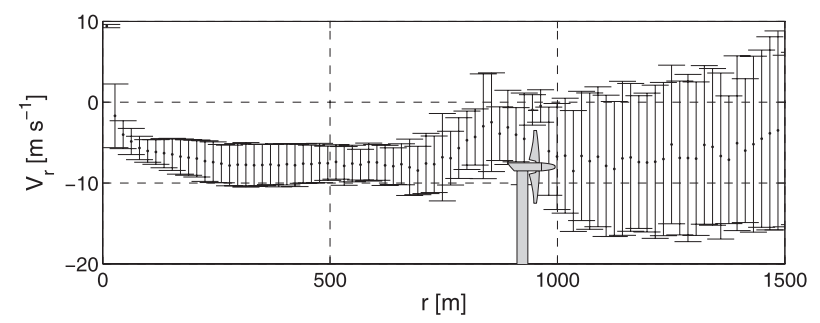

(a)

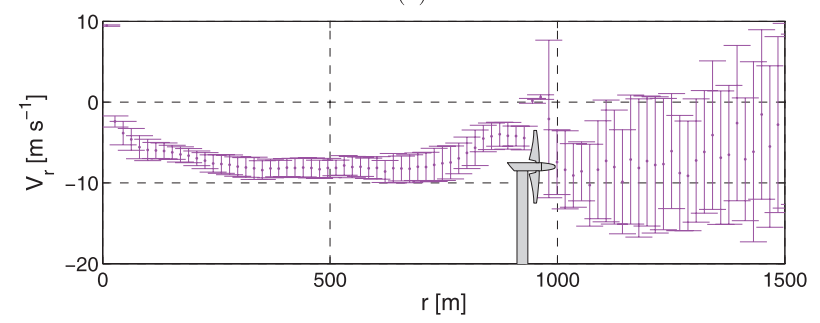

(b)

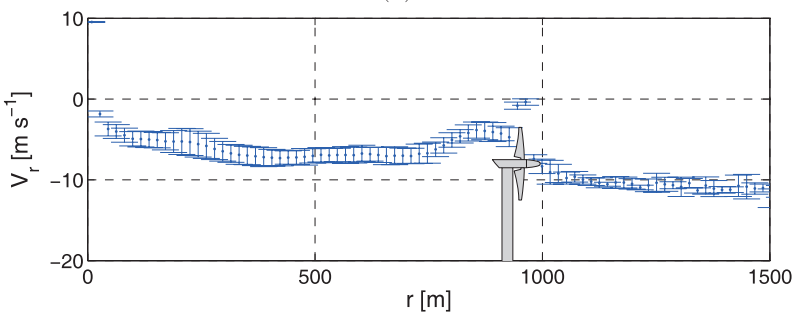

(c)

FIG. 4. Mean value and standard deviation of the radial velocity measured with a different number of emitted rays: (a) 1 ray, (b) 4 rays, and (c) 64 rays.

component retrieved from the radial velocity through geometrical relations that take into account the different elevation angles of the laser beam and by assuming a negligible vertical velocity. The latter is a realistic assumption as reported in different studies (see, e.g., Porté-Agel et al. 2011; Wu and Porté-Agel 2011), and as it will be shown in the following section through simultaneous measurements with two lidars.

From the maps of the axial velocity in Fig. 5, the presence of the wake behind the turbine is evidenced by a clear velocity deficit, which is reduced in the downstream direction due to the recovery of the wake. It should be noted that the wake changes slightly among the different snapshots due to possible variations of the incoming flow or to possible adjustments of the wind turbine yaw angle. The mean axial velocity field was calculated from the snapshots acquired over a period of $15 \mathrm{~min}$ and with roughly uniform conditions of the incoming wind (see Fig. 6). From the plot of the mean wake, the downstream recovery of the velocity deficit is more evident, especially for downstream distances larger than $3 d$.

Vertical profiles of the axial velocity, as the ones reported in Fig. 7, are then evaluated by performing 
(a)

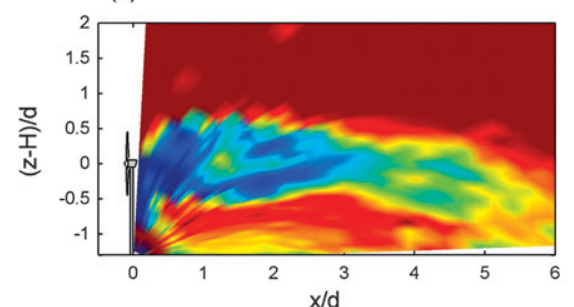

(c)

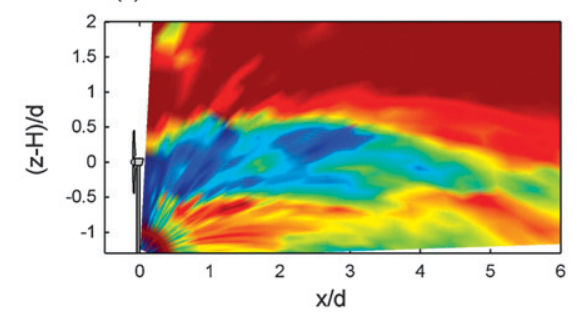

(b)

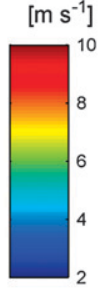

$\left[\mathrm{m} \mathrm{s}^{-1}\right]$

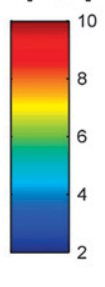

(d)

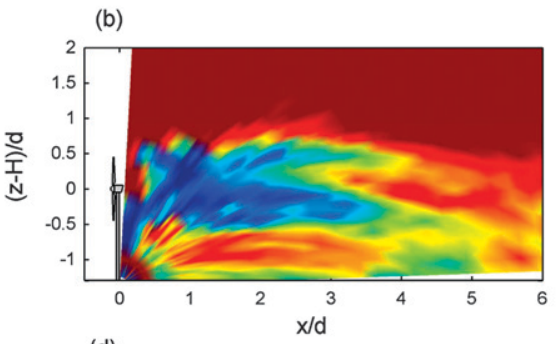

$\left[\mathrm{m} \mathrm{s}^{-1}\right]$

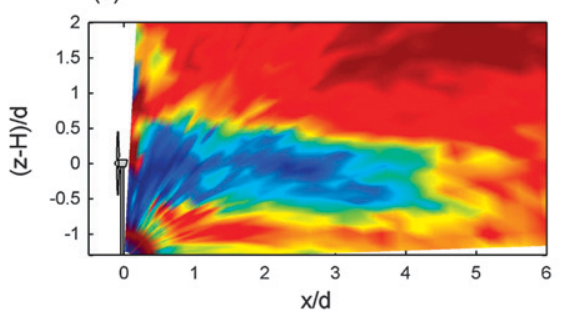

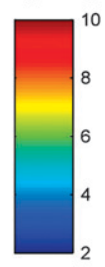

$\left[\mathrm{m} \mathrm{s}^{-1}\right]$

FIG. 5. Snapshots of the axial velocity measured with a single lidar.

Delaunay triangulation of the mean axial velocity map (see Delaunay 1934). From this plot a strong velocity deficit of about $70 \%$ of the incoming wind velocity is observed at hub height for a downstream distance of $0.5 d$; then, the velocity deficit gradually decreases as the wake recovers downstream. It should be pointed out that a substantial error is observed for the velocity profile at $x / d=0.5$ and for locations higher than the turbine top tip, which is due to the backscattering of the laser beam produced by the wind turbine blades and affecting the surrounding measurement points.

Measurements with a single lidar were also performed by staring the laser beam over fixed directions, using one ray and performing 512 measurements over a sampling period of about $11 \mathrm{~min}$ for each tested direction. In particular laser beam directions that cross the turbine top tip height at the downstream distances of $0.5 d, 1 d$, $2 d, 3 d, 4 d$, and $5 d$ were investigated. Considering that the lidar was placed at a distance of $6.5 d$ downstream of the wind turbine along the mean wind direction, the resulting tested elevation angles were $17.7^{\circ}, 19.2^{\circ}, 32.1^{\circ}$, $28.8^{\circ}, 37.7^{\circ}$, and $52.5^{\circ}$, respectively. These tests were performed using one ray, that is, with the maximum sampling frequency of $0.77 \mathrm{~Hz}$, with the goal of investigating wake turbulence. Statistics of these measurements were evaluated, as in Fig. 8, where the mean wind velocity is reported as a function of the vertical position. The typical velocity deficit distribution is detected and the wake recovery is observed as the lidar elevation angle is increased, thus including measurements from farther downstream locations in the wake. It should be noted that these plots show a clear skewness of the velocity deficit

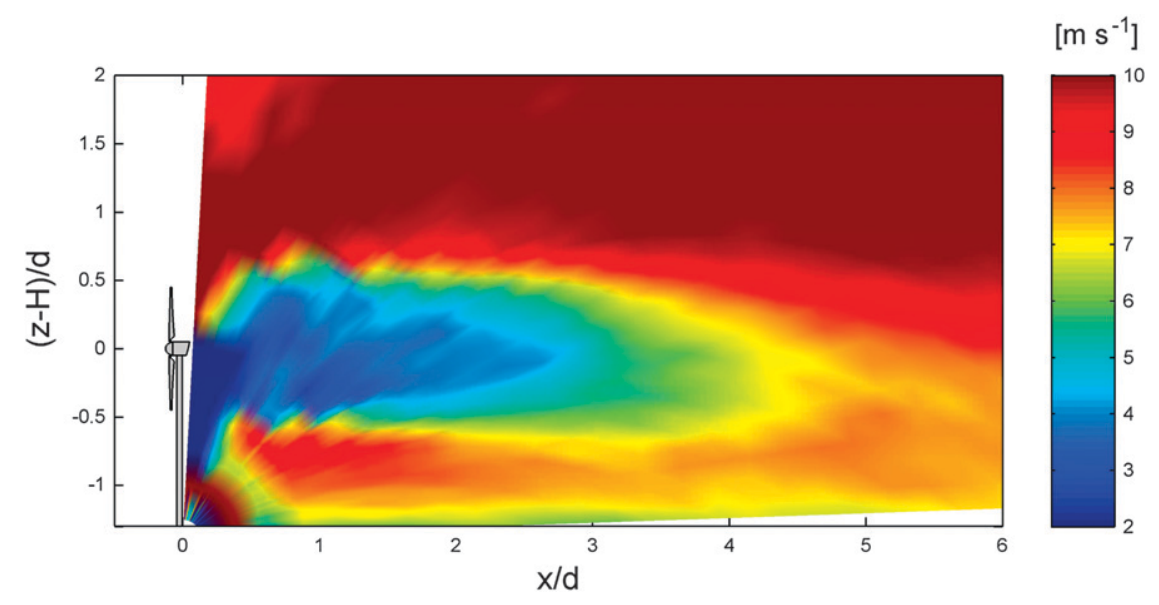

FIG. 6. Map of the mean axial velocity obtained as average of 2D snapshots performed with a single lidar over a sampling period of $15 \mathrm{~min}$. 


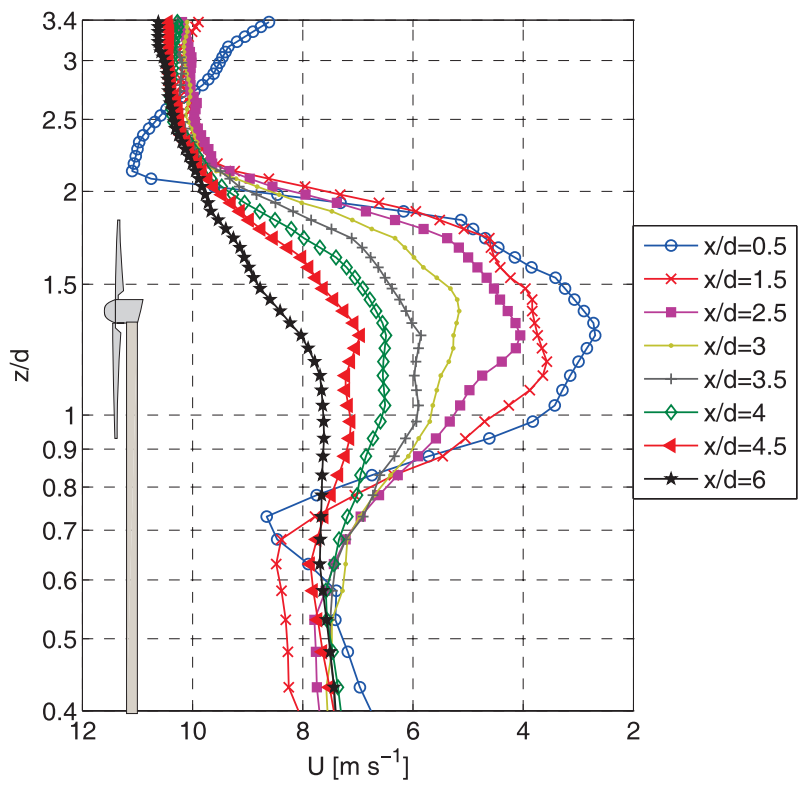

FIG. 7. Vertical profiles of the mean axial velocity measured over the mean vertical symmetry plane of the wake.

toward the upper part of the wake, which is stronger for the lower elevation angles. This is because in those cases, increasing the radial distance from the lidar location leads to an increase in sampling height and a decrease in downstream distance from the turbine-that, in turn, leads to an enhancement of the velocity deficit in the higher part of the wake, compared to the case of a vertical profile. Furthermore, it should be pointed out that the incoming wind significantly changed between the several tested laser elevation angles, as can be observed from the wind profiles with heights higher than the turbine top tip. This feature is due to the relatively long sampling period of $11 \mathrm{~min}$ required for each tested elevation angle of the lidar ray and to the unsteady wind conditions.

Analysis of velocity fluctuations highlights particular locations with increased unsteadiness, as reported in
Fig. 9a, where the standard deviation is plotted as a function of the downstream location. Standard deviation peaks are generally observed for each tested lidar elevation angle, and these peaks move downstream by increasing the laser elevation angle. By plotting the standard deviation as a function of the vertical position (see Fig. 9b), it is evident that all these fluctuation peaks are located at the turbine top tip height. This flow feature represents a wake region with a higher fluctuation level, which is clearly detectable up to a downstream distance of about $3 d$, and it can be a source of potential dangerous fatigue loads for a wind turbine placed downstream within a wind farm. The presence of an enhanced turbulence level in wind turbine wakes for heights comparable to the turbine top tip was already observed from wind tunnel tests of downscaled models (Chamorro and Porté-Agel 2009) and also from LES studies (Wu and Porté-Agel 2011). The increased turbulence in correspondence with the turbine top tip height has a mechanical origin, due to the presence of an increased wind shear produced from the superposition of the wind turbine wake on the incoming atmospheric boundary layer.

Finally, spectral analysis was carried out of the measurements obtained by staring the lidar at the fixed elevation angle of $17.7^{\circ}$, using one ray and 512 measurements (namely, a sampling period of about $11 \mathrm{~min}$ ). In Fig. 10 Fourier power spectral density evaluated with the Welch's method is reported (see Welch 1967) for different locations along the laser beam, which are identified by their vertical position. Interestingly, for all measurements the spectral density of velocity fluctuations shows clear evidence of an inertial subrange, characterized by a slope of $-5 / 3$. The inertial subrange characterizes vorticity structures with turbulent scales smaller than the ones related to very energetic eddies but larger than the ones of viscous eddies. In the inertial subrange, the energy coming from large eddies is in equilibrium with the one dissipated by viscous eddies; thus, the slope of

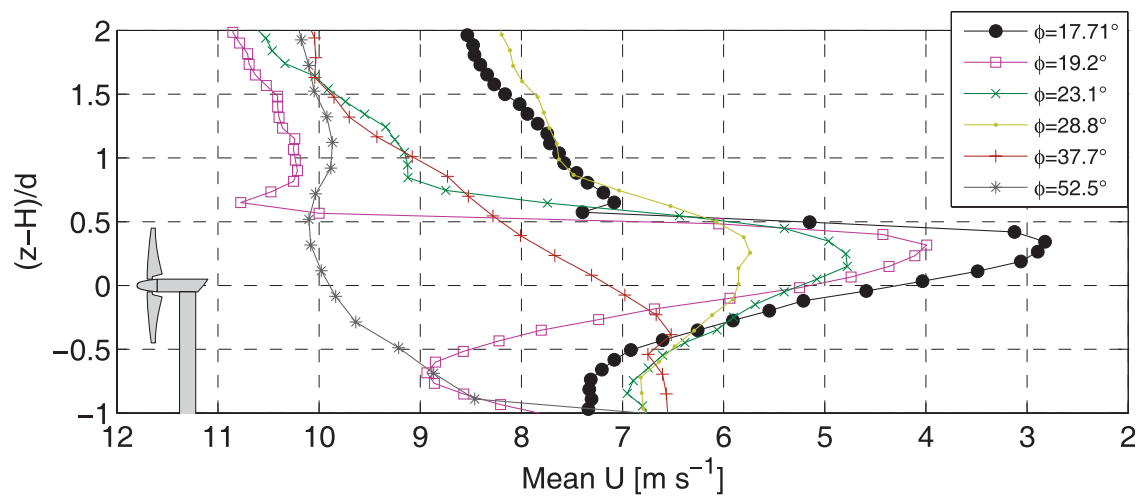

FIG. 8. Mean axial velocity obtained by staring the laser beam over the mean vertical symmetry plane of the wake with different elevation angles. 


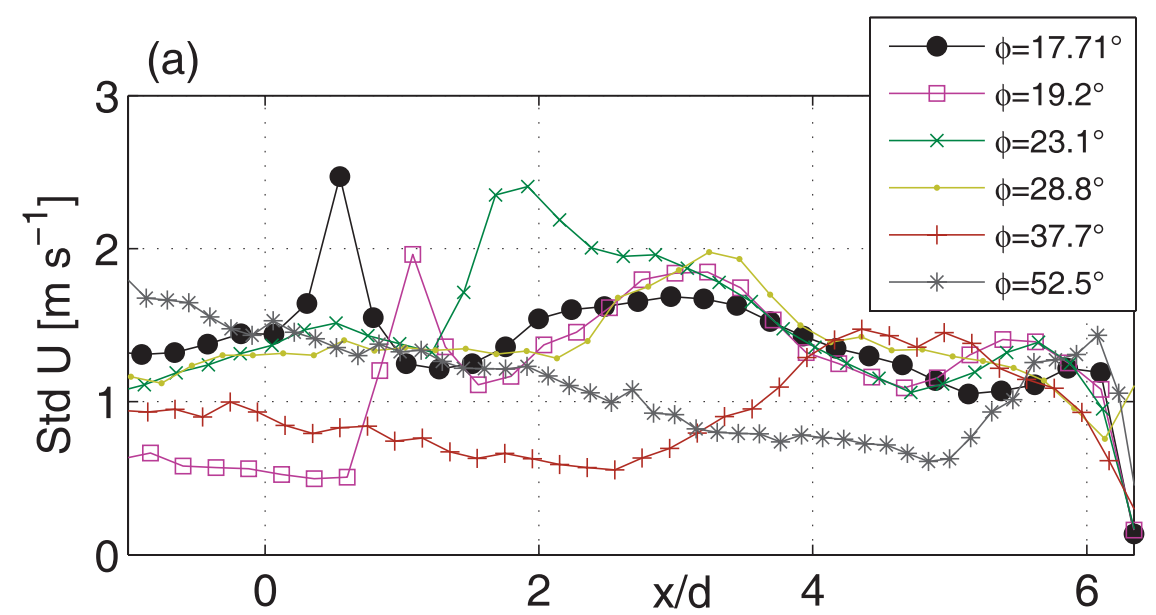

(b)

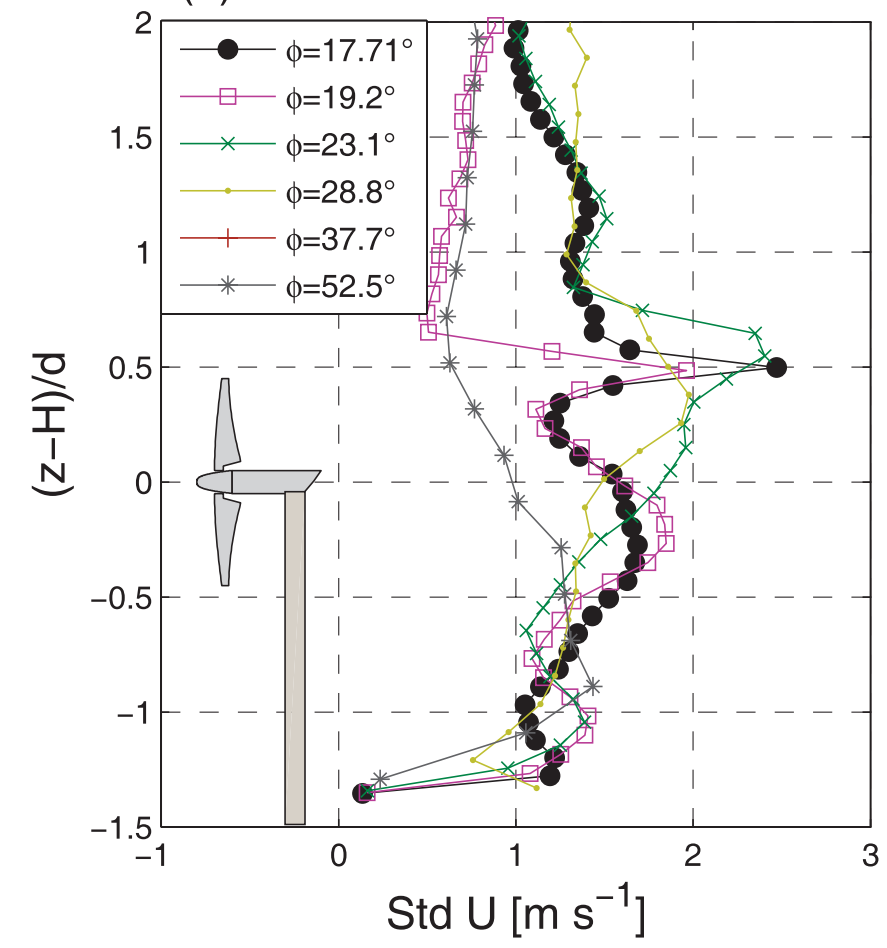

FIG. 9. Standard deviation of the axial velocity obtained by staring the laser beam over the mean vertical symmetry plane of the wake with different elevation angles: (a) standard deviation as a function of the streamwise distance and (b) standard deviation as a function of the vertical position.

the energy spectrum remains with a constant value of $-5 / 3$ (see, e.g., Stull 1988).

\section{Simultaneous measurements with two lidars}

Simultaneous measurements with two lidars were performed over the mean vertical symmetry plane of the wind turbine wake in order to retrieve $2 \mathrm{D}$ velocity fields. For these tests one lidar was placed at the wind turbine location pointing downstream, while a second lidar was placed along the mean wind direction at a downstream distance of $6.5 d$ and pointing upstream. The experimental setup, the radial velocities measured by the two lidars, and the retrieved horizontal and vertical velocities are sketched in Fig. 11. A third lidar was used to characterize the incoming wind. It was located at a downstream distance of $6.5 d$ and a transversal distance of $2 d$ in order to perform measurements over a plane located outside of the 


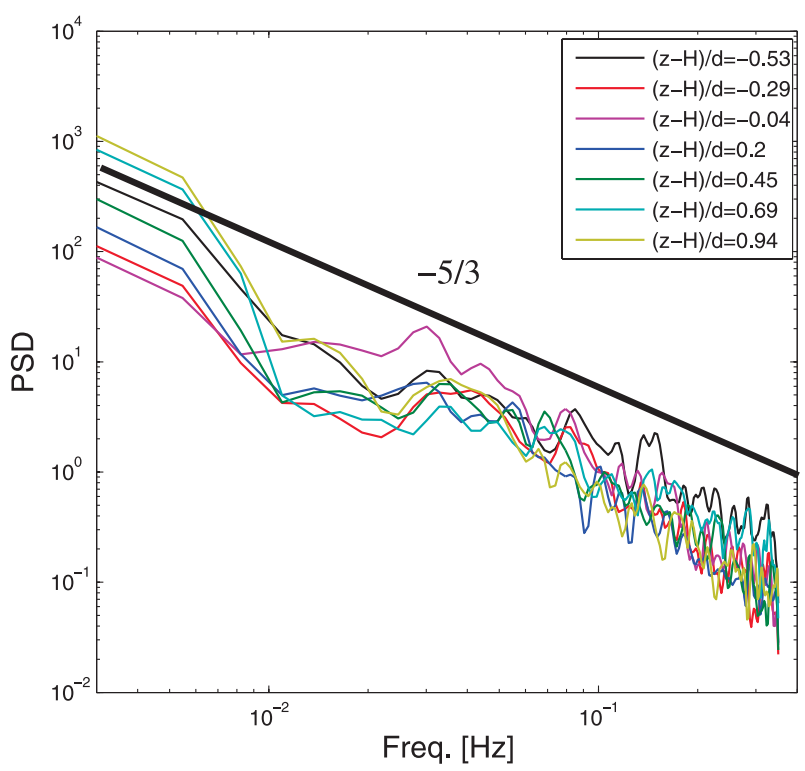

FIG. 10. Fourier spectra evaluated through the Welch's method of the radial velocity signals obtained by staring the laser beam over the mean vertical symmetry plane of the wake.

wake, parallel to the mean vertical symmetry plane of the wake.

Simultaneous measurements were performed by staring the laser beams emitted from the two lidars at the turbine top tip height and different downstream distances $(0.5 d, 1 d, 2 d, 3 d, 4 d, 5 d)$. These tests were performed by using one ray for each velocity profile and by acquiring 256 measurements for each selected laser direction. The radial velocities measured by the two lidars at a location corresponding to the intersection point of the two laser beams are considered. The axial and vertical velocity components are then retrieved through geometrical relations, which take the elevation angles of the laser beams and the two lidar locations into account. It is important to point out that these twodimensional lidar measurements can be considered reliable if the two lidar beams intersected at angles that are not substantially larger or smaller than $90^{\circ}$, in order to characterize both the horizontal and vertical velocity components. For these tests measurement points with intersection angles of the laser rays between $50^{\circ}$ and $130^{\circ}$ were considered.

In Fig. 12a time series of the radial velocity measured by the two lidars are reported for the point at the turbine top tip height and a downstream distance of $0.5 d$. For this measurement point lidar 1, that is, the one located in proximity of the wind turbine location, was pointing downstream with an elevation angle of $75^{\circ}$, while lidar 2 was pointing upstream with an elevation angle of $17.6^{\circ}$; the resulting intersection angle between the two laser beams was $87.4^{\circ}$. For the considered measurement point, lidar 1 was mainly affected by the vertical velocity, indeed in Fig. 12a a very small velocity is detected. On the other hand, lidar 2 detected a radial velocity with a higher magnitude due to the small elevation angle of its laser beam; thus, it was mainly affected by the axial velocity. By moving downstream, the elevation angle of lidar 1 is reduced; thus, it was gradually more affected by the axial velocity and less by the vertical one. Conversely, the elevation angle of the lidar 2 was increased.

Axial and vertical velocity components were then retrieved and their time series are reported in Fig. 12b. Statistics of the two velocity components were computed

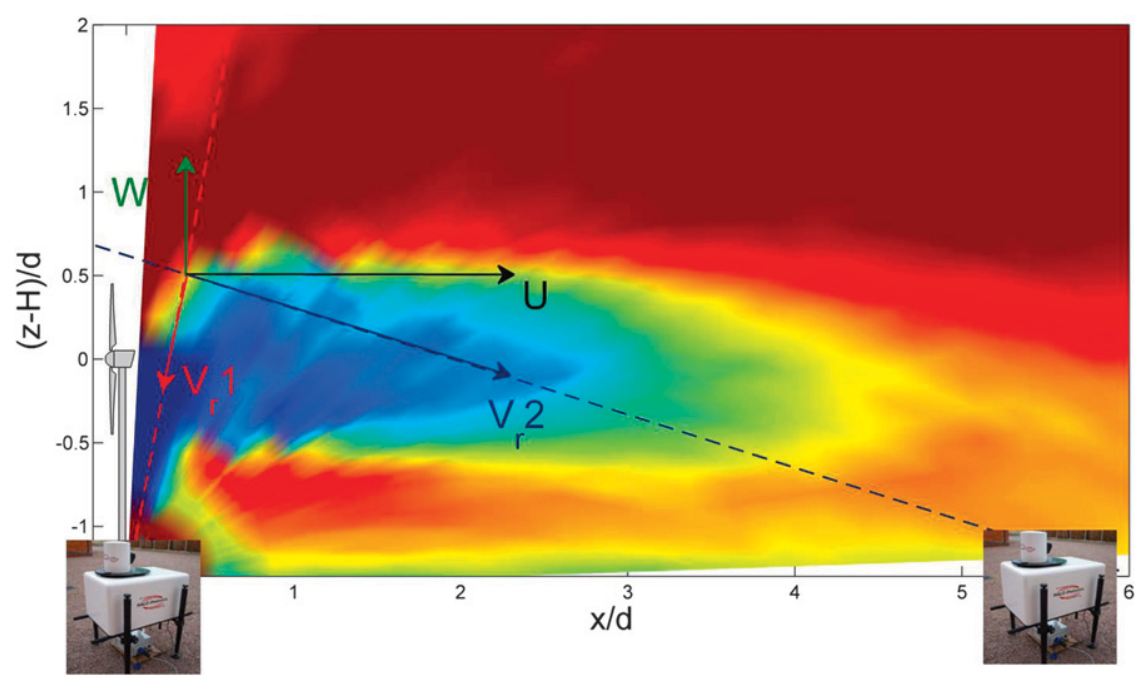

FIG. 11. Sketch of the setup and data retrieval for the simultaneous measurements with two lidars performed over the wake symmetry plane. The first lidar is located at $x / d=0$ and the second one at $x / d=6.5$. 


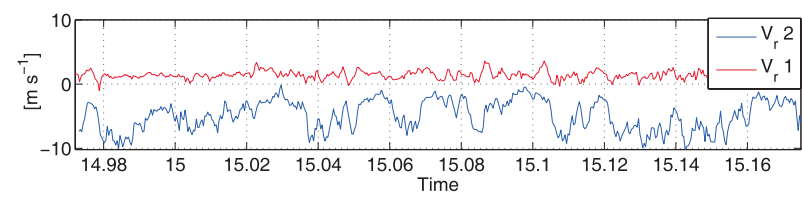

(a)

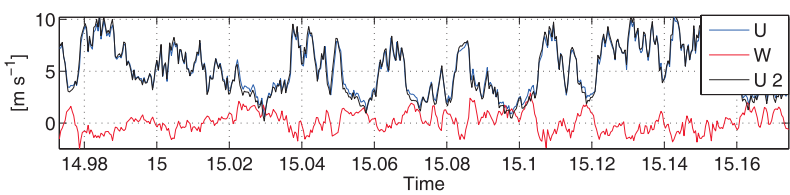

(b)

FIG. 12. Simultaneous measurements with two lidars: (a) time series of the radial velocity, (b) horizontal and vertical velocities ( $U$ and $W$, respectively), and axial velocity retrieved by only using lidar 2 located downstream, $U_{2}$.

for the measurement points located at the turbine top tip height and different downstream locations - in particular, mean value and standard deviation are reported in Fig. 13. The mean vertical velocity is shown to be roughly negligible for all the tested downstream locations, whereas the mean axial velocity is shown to gradually increase by moving downstream due to the wake recovery. Standard deviation of both velocity components confirms the presence of strong velocity fluctuations in correspondence of the turbine top tip height, as already shown in the previous section from the single lidar measurements. In fact, a standard deviation of about $30 \%$ of the mean velocity is detected for downstream distances up to $3 d$, and then turbulence levels start to decrease.

Finally, the axial velocity retrieved by only using the radial velocity measured by lidar 2 and by assuming a negligible vertical velocity is shown in Fig. 12b. It is evident that for this case, for which a laser elevation angle of $17.6^{\circ}$ was set, the axial velocity can be retrieved with a negligible error from measurements performed with a single lidar.

\section{Conclusions}

Field measurements of the wake flow generated from a 2-MW Enercon E-70 wind turbine located in Collonges, Switzerland, were performed using three scanning wind lidars. The Galion Doppler wind lidar, produced by Halo Photonics and used for the present field campaign, has a relatively high spatial resolution of $18 \mathrm{~m}$, which allows a detailed characterization of wind turbine wakes. A GPS-based technique was used to accurately determine the locations of the lidars with respect to the wind turbine. Furthermore, for these tests GPS data were also used to compute the azimuthal and elevation angles of the lidar laser beams.

Tests were carried out with a single lidar by varying the number of laser rays emitted for each measurement,

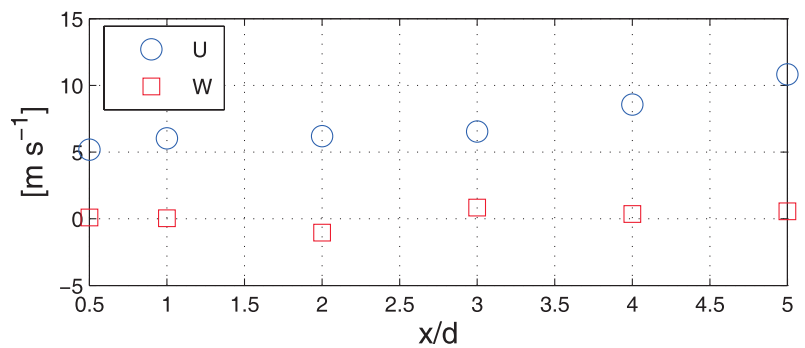

(a)

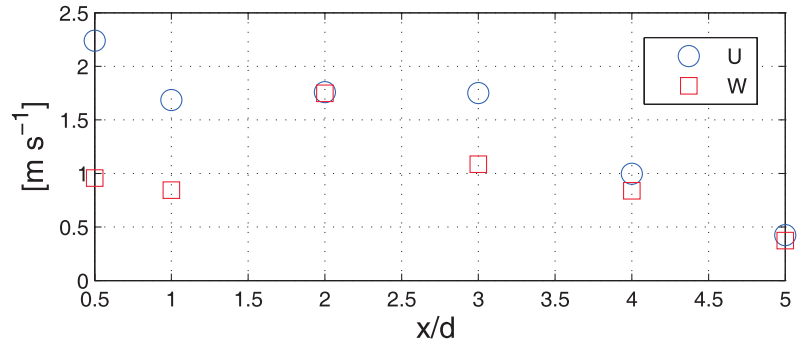

(b)

FIG. 13. Statistics of the axial and vertical velocity components ( $U$ and $W$, respectively) retrieved from simultaneous measurements performed with two lidars: (a) mean value and (b) standard deviation.

thus varying the sampling frequency. Results show that this scanning lidar allows the performance of accurate measurements of the mean wind velocity in turbine wakes. Increasing the number of rays emitted for each measurement helps increase the signal-to-noise ratio for cases with low aerosol concentration or for measurement points at distances larger than $2 \mathrm{~km}$. For wind turbine wake measurements, an adequate signal-tonoise ratio was generally obtained using only one laser ray per measurement, which could be related to wake turbulence and to an increased aerosol concentration produced from the flow entrainment within the wake. It is important to note that the possibility of performing reliable measurements with only one emitted ray enables maximizing the sampling frequency and, thus, investigating wake turbulence.

Measurements with a single lidar were then carried out over the vertical symmetry plane of the wind turbine wake with the maximum sampling frequency of $0.77 \mathrm{~Hz}$. The mean velocity field of the wind turbine wake was obtained by averaging 2D scans consecutively performed. Single lidar measurements were also performed by staring the laser beam at fixed positions for a sampling period of about $11 \mathrm{~min}$ and with the maximum sampling frequency in order to characterize the level of turbulence present in the wake. From these tests, a peak in the velocity variance was detected at the turbine top tip height, which could represent a source of dangerous fatigue loads for following wind turbines within a wind 
farm. The spectral density of the measured velocity signals shows evidence of a clear $-5 / 3$ scaling characteristic of the inertial subrange of turbulence.

Finally, simultaneous measurements with two lidars were performed over the mean vertical symmetry plane of the wake, while a third lidar measured the incoming wind over a vertical plane parallel to the mean wind direction. From these measurements streamwise and vertical velocity components were retrieved for measurement points located at the turbine top tip height and different downstream locations. These tests have shown that the mean vertical velocity is practically negligible for all the considered downstream locations, while the axial velocity gradually increases by moving downstream due to wake recovery. The turbulence in both velocity components has a peak of about $30 \%$ of the mean velocity up to a downstream distance of three rotor diameters; farther downstream turbulence intensity starts to decrease. The presence of enhanced wake turbulence for locations at the turbine top tip height is considered to be a typical feature for wind turbine wakes; however, the amount of added turbulence can vary as a function of the wind turbine type, wind conditions, terrain roughness, and surrounding topography.

Currently, simultaneous measurements with three lidars are underway in order to retrieve three velocity components within a wind turbine wake. Future lidar campaigns will consider investigations on the topography effect on wind power production and also the analysis of wind turbine wake interactions within a wind farm.

Acknowledgments. This research was supported by the Swiss National Science Foundation (Grant 200021_ 132122) and the Swiss Federal Office of Energy. The authors are grateful to J. M. Rouiller (Comune de Lausanne), N. Mettan (RhôneEole), P. A. Clivaz and J. Antonin (SEIC-TELEDIS Groupe), O. Khole, H. Nusbaumer, and T. Delavy (KholeNusbaumer SA) for their support in the preparation of the field campaign and providing wind turbine SCADA data. Computing resources were provided by the Minnesota Supercomputing Institute and the Swiss National Supercomputing Centre (CSCS) under the project s306.

\section{REFERENCES}

Aitken, M. L., M. E. Rhodes, and J. K. Lundquist, 2012: Performance of a wind-profiling lidar in the region of wind turbine rotor disks. J. Atmos. Oceanic Technol., 29, 347-355.

Alfredsson, P. H., F. H. Bark, and J. A. Dahlberg, 1980: Some properties of the wake behind horizontal axis wind turbines. Proc. Third Int. Symp. on Wind Energy Systems, Lyngby, Denmark, BHRA Fluid Engineering, 469-484.
_ J. A. Dahlberg, and P. E. J. Vermeulen, 1982: A comparison between predicted and measured data from wind turbine wakes. Wind Eng., 6, 149-155.

Alinot, C., and C. Masson, 2002: Aerodynamic simulations of wind turbines operating in atmospheric boundary layer with various thermal stratifications. Proc. ASME Wind Energy Symp., Reno, NV, ASME, WIND2002-42, 206-215.

Amar, F. B., M. Elamouri, and R. Dhifaoui, 2008: Energy assessment of the first wind farm section of Sidi Daoud, Tunisia. Renewable Energy, 33, 2311-2321.

Belu, R., and D. Koracin, 2009: Wind characteristics and wind energy potential in western Nevada. Renewable Energy, 34, 2246-2251.

Builtjes, P. J. H., 1978: The interaction of windmill wakes. Proc. Second Int. Symp. on Wind Energy Systems, Amsterdam, Netherlands, BHRA, B5-49-B5-58.

Cal, R. B., J. Lebron, L. Castillo, H. S. Kang, and C. Meneveau, 2010: Experimental study of the horizontally averaged flow structure in a model wind-turbine array boundary layer. J. Renewable Sustainable Energy, 2, 013106, doi:10.1063/1.3289735.

Calaf, M., C. Meneveau, and J. Meyers, 2010: Large eddy simulation study of fully developed wind-turbine array boundary layers. Phys. Fluids, 22, 015110, doi:10.1063/1.3291077.

Calhoun, R., R. Heap, M. Princevac, R. Newsom, H. Fernando, and D. Lingon, 2006: Virtual towers using coherent Doppler lidar during the Joint Urban 2003 dispersion experiment. J. Appl. Meteor. Climatol., 45, 1116-1126.

Chamorro, L. P., and F. Porté-Agel, 2009: A wind-tunnel investigation of wind-turbine wakes: Boundary-layer turbulence effects. Bound.-Layer Meteor., 132, 129-149.

— and - 2010: Effects of thermal stability and incoming boundary-layer flow characteristics on wind-turbine wakes: A wind-tunnel study. Bound.-Layer Meteor., 136, 515-533.

— and - 2011: Turbulent flow inside and above a wind farm: A wind-tunnel study. Energies, 4, 1916-1936.

Chan, P. W., and A. M. Shao, 2007: Depiction of complex airflow near Hong Kong International Airport using a Doppler lidar with a two-dimensional wind retrieval technique. Meteor. Z., 16, 491-504.

Crespo, A., J. Hernández, and S. Frandsen, 1999: Survey of modelling methods for wind turbine wakes and wind farms. Wind Energy, 2 (1), 1-24.

Delaunay, B., 1934: Sur la sphère vide. Izv. Akad. Nauk SSSR, Otd. Mat. Estestv. Nauk, 7, 793-800.

Drechsel, S., M. Chong, G. Mayr, M. Weissmann, R. Calhoun, and A. Dörnbrack, 2009: Three-dimensional wind retrieval: Application of MUSCAT to dual Doppler lidar. J. Atmos. Oceanic Technol., 26, 635-646.

El Kasmi, A., and C. Masson, 2008: An extended $k-\varepsilon$ model for turbulent flow through horizontal-axis wind turbines. J. Wind Eng. Ind. Aerodyn., 96, 103-122.

Emeis, S., M. Harris, and R. Banta, 2007: Boundary-layer anemometry by optical remote sensing for wind energy applications. Meteor. Z., 16, 337-347.

Frelich, R., S. M. Hannon, and S. W. Henderson, 1998: Coherent Doppler lidar measurements of wind field statistics. Bound. Layer Meteor., 86, 233-256.

Gal-Chen, T., M. Xu, and W. L. Eberhard, 1992: Estimations of atmospheric boundary layer fluxes and other turbulence parameters from Doppler lidar data.J. Geophys. Res., 97 (D17), 409-423.

Gomez-Elvira, R., A. Crespo, E. Migoya, F. Manuel, and J. Hernandez, 2005: Anisotropy of turbulence in wind turbine wakes. J. Wind Eng. Ind. Aerodyn., 93, 797-814. 
Green, D. R. R., 1986: Near wake wind tunnel studies. Loughborough University Tech. Rep. ETSU-WN-5040/1, 60 pp.

— , and A. J. Alexander, 1985: Measurement of velocity and turbulence profiles in flow situations relevant to windturbine performance. Loughborough University Tech. Rep. ETSUWN-5003/1, Government Document E/5A/CON/5003/177/ 026, $262 \mathrm{pp}$.

Hill, M., R. Calhoun, H. Fernando, A. Wieser, A. Dörnbrack, M. Weissmann, G. Mayr, and R. Newsom, 2010: Coplanar Doppler lidar retrieval of rotors from T-REX. J. Atmos. Sci., 67, 713-729.

Jimenez, A., A. Crespo, E. Migoya, and J. Garcia, 2007: Advances in large-eddy simulation of a wind turbine wake. J. Phys., 75, 012041, doi:10.1088/1742-6596/75/1/012041.

,,--- _ and — - 2008: Large-eddy simulation of spectral coherence in a wind turbine wake. Environ. Res. Lett., 3, 015004, doi:10.1088/1748-9326/3/1/015004.

Kasler, Y., S. Rahm, R. Simmet, and M. Kühn, 2010: Wake measurements of a multi-MW wind turbine with coherent longrange pulsed Doppler wind lidar. J. Atmos. Oceanic Technol., 27, 1529-1532.

Kongara, S., R. Calhoun, A. Choukulkar, and M. Boldi, 2010: Velocity retrieval for coherent Doppler lidar. Int. J. Remote Sens., 33, 3596-3613.

Lin, C., Q. Xia, and R. Calhoun, 2008: Retrieval of urban boundary layer structures from Doppler lidar data. Part II: Proper orthogonal decomposition. J. Atmos. Sci., 65, 21-42.

Lu, H., and F. Porté-Agel, 2010: A modulated gradient model for large-eddy simulation: Application to a neutral atmospheric boundary layer. Phys. Fluids, 22, 015109, doi:10.1063/1. 3291073 .

— farm in a stable atmospheric boundary layer. Phys. Fluids, 23, 065101, doi:10.1063/1.3589857.

Mann, J., and Coauthors, 2009: Comparison of 3D turbulence measurements using three staring wind lidars and a sonic anemometer. Meteor. Z., 18, 135-140.

Markfort, C. D., W. Zhang, and F. Porté-Agel, 2012: Turbulent flow and scalar transport through and over aligned and staggered wind farms. J. Turbul., 13, N33, doi:10.1080/14685248. 2012.709635.

Medici, D., and P. Alfredsson, 2006: Measurements on a wind turbine wake: 3D effects and bluff body vortex shedding. Wind Energy, 9, 219-236.

Milborrow, D. J. and J. N. Ross, 1983: The influence of turbulence and rotor thrust on wind turbine wake characteristics. Central Electricity Research Laboratories Tech. Memo. TPRD/L/AP/ 0098/M83, 17 pp.

Newsom, R., D. Ligon, R. Calhoun, R. Heap, E. Cregan, and M. Pricevac, 2005: Retrieval of microscale wind and temperature fields from single- and dual-Doppler lidar data. J. Appl. Meteor., 44, 1324-1345.

_, R. Calhoun, R. Lingon, and J. Allwine, 2008: Linearly organized turbulence structures observed over a suburban area by dual-Doppler lidar. Bound.-Layer Meteor., 127, 111-130.

Porté-Agel, F., Y.-T. Wu, H. Lu, and R. Conzemius, 2011: Largeeddy simulation of atmospheric boundary layer flow through wind turbines and wind farms. J. Wind Eng. Ind. Aerodyn., 99, 154-168.

Retallack, C., R. Calhoun, H. J. S. Fernando, K. Rayner, A. Stuart, J. Sutton, and M. F. Hibberd, 2010: Flow and pollution transport during Wagerup 2006: A case study. Meteor. Appl., 17, 269-278.

Ross, J. N., 1979: Measurements of velocity in wind tunnel studies of windmill arrays using laser anemometry. Central Electricity Research Laboratories Tech. Rep. LM/Phys./133, 5 pp.

— , and J. Ainslie, 1981: Wake measurements in clusters of model wind turbines using laser Doppler anemometry. Proc. Third BWEA Wind Energy Conf., Cranfield, United Kingdom, British Wind Energy Association, 17284.

Sathe, A., J. Mann, J. Gottschall, and M. Courtney, 2011: Can wind lidars measure turbulence? J. Atmos. Oceanic Technol., 28, 853-868.

Sezer-Uzol, N., and L. N. Long, 2006: 3-D time-accurate CFD simulations of wind turbine rotor flow fields. Proc. 44th AIAA Aerospace Sciences Meeting and Exhibit, Reno, NV, AIAA, 2006-0934, 23 pp. [Available online at http://nsezeruzol.etu. edu.tr/publications/AIAA06-394.pdf.]

Sørensen, J. N., J. A. Michelsen, and S. Schreck, 2002: NavierStokes predictions of the NREL phase VI rotor in the NASA Ames $80 \mathrm{ft} \times 120 \mathrm{ft}$ wind tunnel. Wind Energy, 5, 151-169.

Stull, R. B., 1988: An Introduction to Boundary Layer Meteorology. Kluwer Academic, 666 pp.

Talmon, A. M., 1985: The wake of a horizontal axis wind turbine model, measurements in uniform approach flow and in a simulated boundary layer. TNO Division of Technology for Society Tech. Rep. 85-01021.

Tongchipakdee, C., S. Benjanirat, and L. N. Sankar, 2005: Numerical simulation of the aerodynamics of horizontal axis wind turbines under yawed flow conditions. J. Sol. Energy Eng., 127, 464-475.

Vermeer, L. J., J. N. Sørensen, and A. Crespo, 2003: Wind turbine wake aerodynamics. Prog. Aerosp. Sci., 39, 467-510.

Vermeulen, P. E. J., and P. J. H. Builtjes, 1982: Turbulence measurements in simulated wind turbine clusters. TNO Division of Technology for Society Tech. Rep. 82-03003, 12 pp.

Wagner, R., I. Antoniou, S. M. Pedersen, M. S. Courtney, and H. E. Jorgensen, 2009: The influence of the wind speed profile on wind turbine performance measurements. Wind Energy, 12, 348-363.

Welch, P. D., 1967: The use of fast Fourier transform for the estimation of power spectra: A method based on time averaging over short, modified periodograms. IEEE Trans. Audio Electroacoust., AU-15, 70-73.

Wu, Y.-T., and F. Porté-Agel, 2011: Large-eddy simulation of wind-turbine wakes: Evaluation of turbine parametrisations. Bound.-Layer Meteor., 138, 345-366.

— and - 2013: Simulation of turbulent flow inside and above wind farms: Model validation and layout effects. Bound.Layer Meteor., doi:10.1007/s10546-012-9757-y, in press.

Xia, Q., C. Lin, R. Calhoun, and R. Newsom, 2008: Retrieval of urban boundary layer structures from Doppler lidar data. Part I: Accuracy assessment. J. Atmos. Sci., 65, 3-20.

Xu, G., and L. N. Sankar, 2000: Computational study of horizontal axis wind turbines. J. Sol. Energy Eng., 122, 35-39.

Zhang, W., C. D. Markfort, and F. Porté-Agel, 2012: Near-wake flow structure downwind of a wind turbine in a turbulent boundary layer. Exp. Fluids, 52, 1219-1235, doi:10.1007/ s00348-011-1250-8.

,-- , and -2013 : Wind-turbine wakes in a convective boundary layer: A wind-tunnel study. Bound.-Layer Meteor., 146, 161-179, doi:10.1007/s10546-012-9751-4. 